\title{
The Improved Hatch Cover Construction for Universal Open Box-type Wagon from the Strength and Durability Point of View
}

\author{
Oleksij Fomin ${ }^{1}$, Juraj Gerlici², Alyona Lovska ${ }^{3}$, Mykola Gorbunov ${ }^{4}$, Kateryna Kravchenko ${ }^{2}$, Pavlo Prokopenko ${ }^{5}$, Vladi- \\ mir Hauser ${ }^{2}$ \\ ${ }^{1}$ Faculty of Railway Infrastructure and Rolling Stock, State University of Infrastructure and Technology, Kyrylivska str., \\ 9,04071 Kyiv. Ukraine. E-mail: fomin1985@ukr.net \\ ${ }^{2}$ Faculty of Mechanical Engineering, University of Žilina, Univerzitná 1, 01026 Žilina. Slovak Republic. E-mail: ju- \\ raj.gerlici@fstroj.uniza.sk, kkatherina@ukr.net, vladimir.hauser@fstroj.uniza.sk \\ ${ }^{3}$ Faculty of Mechanics and Energy, Ukrainian State University of Railway Transport, Feuerbach Square 7, Kharkov \\ 61050. Ukraine. E-mail: alyonaLovskaya.vagons@gmail.com \\ ${ }^{4}$ Educational and Scientific Institute of Transport and Logistics, Volodymyr Dahl East Ukrainian National University, \\ Central Avenue 59a, 93400 Sewerodonetsk. Ukraine. E-mail: gn0255@mail.ru \\ ${ }^{5}$ Branch "Research and design and technological Institute of Railway Transport «PJSC«Ukrzaliznytsya» Ivana Fedorova, \\ 39, 03038 Kyiv. Ukraine. E-mail: prokopenko1520mm@gmail.com
}

\begin{abstract}
Dynamic load of the improved hatch cover construction for universal open-box type wagon is researched, taking in to account the worse loading scheme - impact of $150 \mathrm{~kg}$ cargo from height of $3000 \mathrm{~mm}$. In the case of improved hatch cover construction, dynamic load character reduction up to $50 \%$ can be reached, compare to conventional one. Hatch cover model of proposed construction for strength calculation was created. Strength calculation is done by finite-elements method in Cosmos Works software. Calculation of hatch cower durability, considering symmetrical and asymmetrical load cycle are carried out. In the proposed construction, areas with maximum equivalent stresses caused by usual operational load are defined. Results of conducted research can be useful for projection of new wagon generation with improved technical, economical and operational parameters.
\end{abstract}

Keywords: open box-type cargo wagon, hatch cover, structural analysis, fatigue analysis

\section{Introduction}

One of the main factors of successful state economics development is coordinated function of the transport industry. It is well known that one of the most perspective transport method is railway transport [1-3]. Transportation of bulk freight, which constitute a significant part of total freight, is carried out by open-type wagons [4-6]. Analysis of the statistical data of open-type wagon carrying structure damages allowed to conclude that one of the most problematic elements are the hatch covers. In order to ensure the open wagons operation efficiency, it is necessary to intervent in existing heach cover structures, develop and implement them.

\section{Analysis of recent researchs}

Perspective for improving the open wagon construction are investigated in [6]. It is proposed to increase the open wagons lifetime by improving the construction parameters, for example by using of materials with improved characteristics.

Analysis of the materials structure properties used for bodies of new wagons generation is given in [7]. The work describe advantages of using new modern materials for wagon components designs. But to the issue of improving hatch cover structural features, attention is not given.

Investigation of the open wagon body carying structure strength by falling of cargo material to the wagon floor when loading is given in [8]. It is found out that the maximum equivalent stresses in the carrying structure exceed the allowed values. To ensure the open wagon body strength, usage of elastic bindings in its carrying structures is proposed. It is important to note that the research has been carried out for flat, closed-bottom wagon, so investigation of the hatch covers durability is not carried out.

Efforts to improve the open wagon body carrying structure in order to ensure their attachment reliability with the focus on the transport on the deck of the railway ferry are given in [9]. Body strength calculations results are given in the work, taking into account wagon fixation relative to the deck by proposed structural units in conditions of sea sailing. However, problem of the strength prediction of the open wagon hatch cover is not considered.

Determination of the strength indicators for open wagon hatch cover when loading the pieces of bulk cargo is carried out in [10]. The results of provided calculation allowed to conclude that the typical design of the hatch cover does not meet the strength requirements. Investigation of the open wagon hatch cover durability under other load schemes in usual operation is not carried out in that research.

Interventions in order to improve the hatch cover construction of the hatch of open wagon are given in $[11,12]$. The key feature of the proposed design is a change of the sheet profile, which in the area of the mount has stepped shape that provides support to the inner sheet of the wagon hatch cover.

Advantages of aluminum alloys implementation in the rolling stock construction are given in [13]. The structural features of cargo wagons, as well as high-speed rolling stock, carryng structures of which are made from aluminum are considered. 
Structural analysis of the modified cargo wagon bogie construction are carried out in [14-16]. Strength calculation based on finite element method in Ansys software are presented.

It should be noted that these works does not deal with strength and durability study of the hatch cover for open wagon under usual operational load conditions.

\section{Proposed solution}

In order to ensure the hatch cover strength under operating load conditions, it is proposed to use a multimaterial sandwich in its construction (Fig. 1). The hatch cover consists of two horizontal sheets, between which is placed a substance with elastic-viscous damping properties. The aligment of the cover to the hatch is ensured by $\mathrm{W}$-shaped profile bent sheet (Fig. 1c) and Fig. 1d)) filled with elastic (elastic-viscous) material along the perimeter of the cover, as well as in the middle part. Its height is adapted to install this elements by standard mounting to the open wagon spine beam and to the lower girth. The cover hinge joints are attached to the hatch by welding. The brackets are facing to the bindings on side of lower walls by a typical construction.

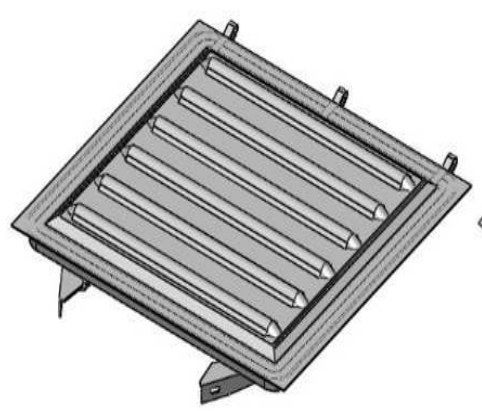

a)

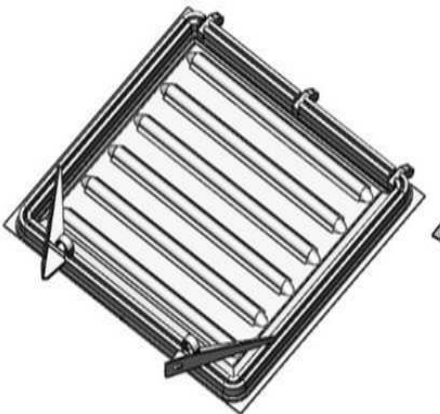

b)

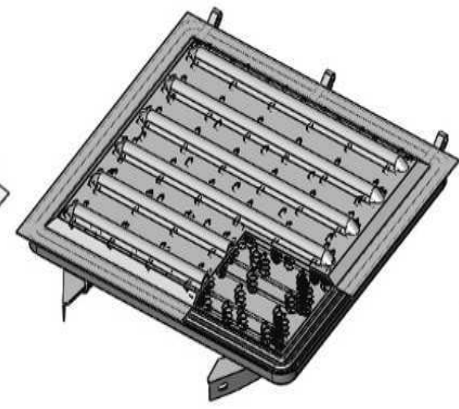

c)

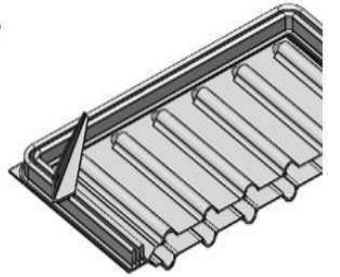

d)

Fig. 1 Proposed construction of the hatch cover for open-type wagon: a) Top view; b) Bottom view; c) Placement of the elastic element in the hatch cover; d) the cross-section of the hatch cover

In order to chceck the changed structure of the hatch cover with additional elastic-viscous connection, studies of its load in the most unfavorable load case have been carried out - an impact weight of $150 \mathrm{~kg}$ from height of $3.0 \mathrm{~m}[17,18]$ was simulated by mathematical model:

$$
M_{h C} \cdot \ddot{z}+c \cdot z=0 \text {, }
$$

where

$M_{h C}$ - mass of cover, [kg];

$c$-stiffness of the cover, [N/m].

To determine the stiffness of the hatch cover when impact falls to it, the formula:

$$
c=P / f
$$

was used, where $P$ - is the force acting on the hatch cover, [N],

$f$-is the deflection of the hatch cover under the action of the load $P,[\mathrm{~m}]$.

Numerical value of the hatch cover deflection is obtained from the strength calculations, realized by the finite element method.

As a generalized coordinate, the movement of the hatch cover relative to the vertical axis $Z$ which passes through its center of mass is considered (Fig. 2).

By calculations carried out in the Mathcad software environment, graphical dependence of hatch cover accelerations (Fig. 3) for boht - typical (1) and proposed (2) solution were obtained.

In Fig. 3 can be seen that in case of proposed hatch cover features construction, the dynamic load acting on it can be reduced in the most unfavorable loading cycle by $50 \%$.

For the hatch cover strength study under operational load conditions, the finite element method was calculated.

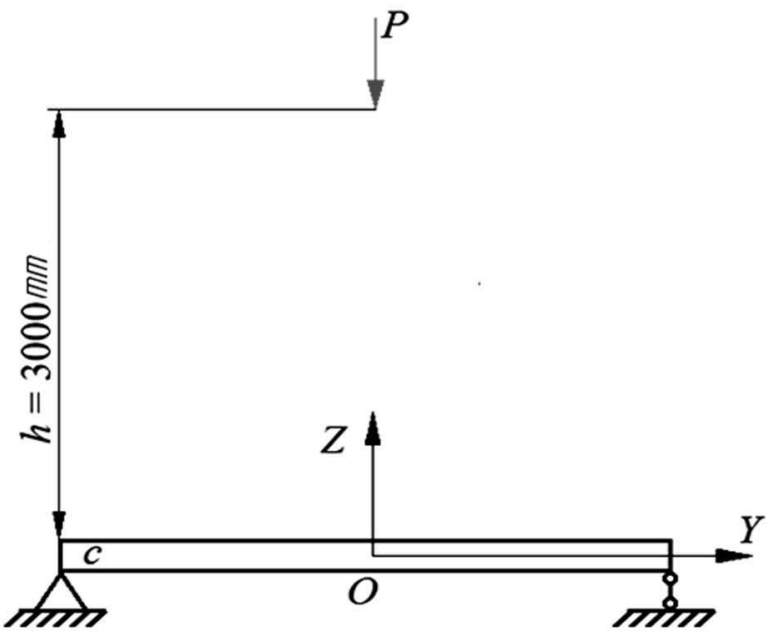

Fig. 2 Calculation scheme of the hatch cover when a impact load of $150 \mathrm{~kg}$ falls from $3000 \mathrm{~mm}$ height on it

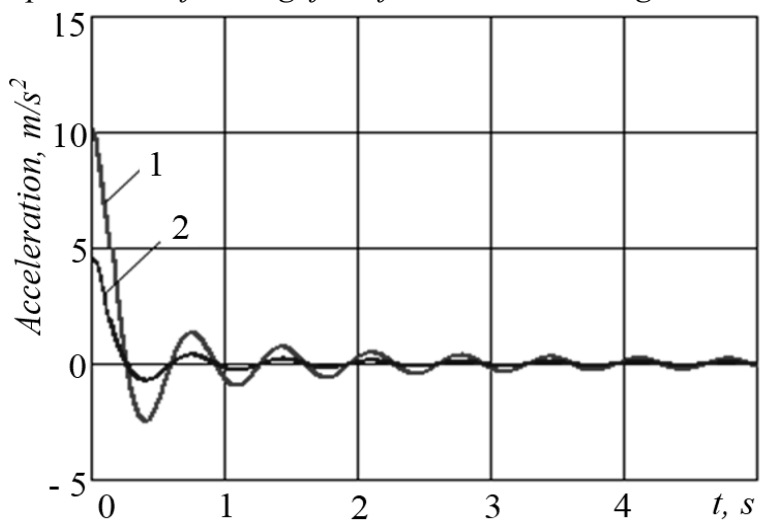


Fig. 3 Accelerations of the hatch cover centre when an impact of $150 \mathrm{~kg}$ from height of $3000 \mathrm{~mm}$ falls on it

The finite-element model of the hatch cover is shown in Fig. 4. The optimal number of mesh elements is determined using the graph-analytic method. Mesh elements number is 236097 , nodes number is 75025 . The maximum size of the mesh element is $40.78 \mathrm{~mm}$, the minimum size is $8.16 \mathrm{~mm}$, maximum aspect ratio of the elements is 78582 . Percentage of elements with ratio less than three is 26.2 , more than ten is 12.8 .

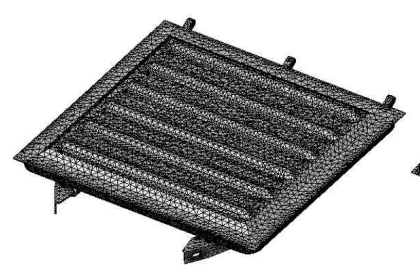

a)

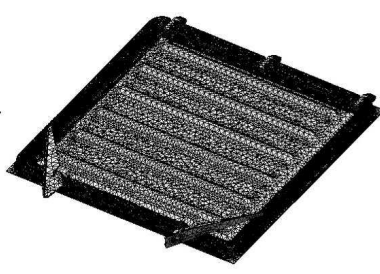

b)
Fig. 4 Finite element model of the proposed hatch cover: a) top view; b) bottom view

The hatch cover strength study was carried out for the load diagrams as presented in $[17,18,20]$, as well as additional:

- hatch cover opening when emptying wagon, without taking into account work of the torsion spring(s), non-simultaneously latches opening (one after another), shock of the cover to the wagon frame spine beams due maximum opening angle.

- non-simultaneous latches opening - one hatch of the loaded wagon is blocked, thus cover is held by one latche and one hinge;

- closing the cover of unloaded wagon by a crowbar.

Computer model of the hatch cover for strength calculation with area of uniformly distributed load $P_{v}=69.9$ $k N$, which consists of the gross weight force on the cover and dynamic load, is shown in Fig. 5. Fixing of the model was applyed to the earpiece of the cover. For modeling the interaction of the cover with the locking device, an additional surface was defined, the area of which is identical to the geometry of this elements contact. To these surfaces were applied reactions $P_{s}$, that arise in the hatch from the action of vertical load $P_{v}$ on the cover.

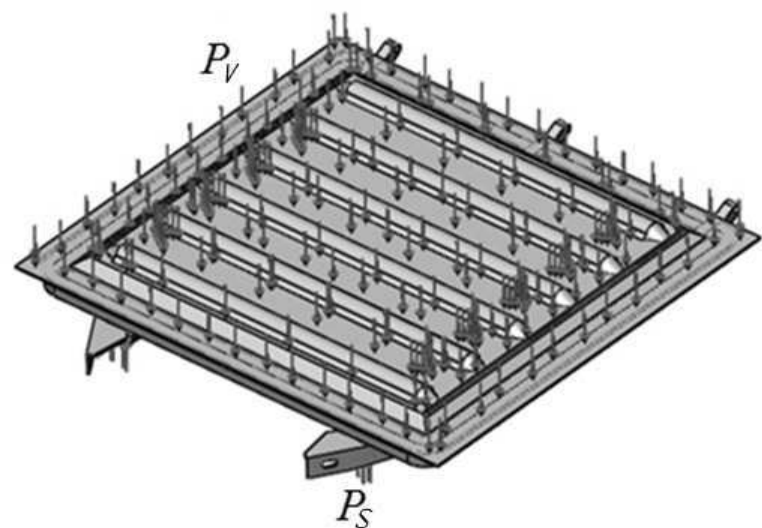

Fig. 5 Hatch cover model for strength calculation

For construction, steel grade 09G2S with yield strength of $345 \mathrm{MPa}$ and strength limit of $490 \mathrm{MPa}$ was used. $[17,18]$.

Hatch cover strength calculating results under this load scheme are shown in Fig. 6. Maximum equivalent stresses arise in the area of rounding ribs to the horizontal plane on the side of locking latches, values about 170 $\mathrm{MPa}$ are reached. Maximum displacements of the structural features are reached on the unlocked fixture, values of displacement reached $7 \mathrm{~mm}$, maximum deformations is $1.2 \cdot 10^{-1}$. It can be concluded, that under this load scheme hatch cover strength is ensured.
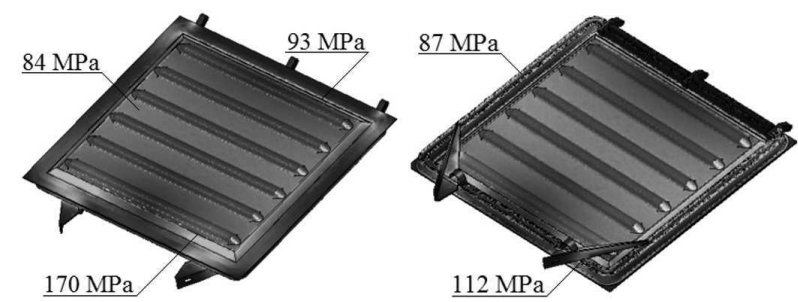

a)

b)

Fig. 6 Stress state of the hatch cover: a) top view; b) bottom view

Strength calculation results of the hatch cover when distributed load $P_{6}=50 \mathrm{kN}$ acting on the centre to the area of $25 \times 25 \mathrm{~cm}$ showed that the maximum equivalent stress occurs in the area of rounding ribs to the horizontal plane on the hinges side and reaches about $140 \mathrm{MPa}$, the maximum displacement in the nodes of the structure are about $4 \mathrm{~mm}$, the maximum deformation was $7.91 \cdot 10^{-3}$. That is, the strength of the hatch cover is ensured.

Proposed construction of the hatch cover is intended for the action of cyclic shock loads, the numerical value of which equals 500. The fatigue curve is obtained on the basis of the 09G2C grade steel elastic modulus. Performed calculations made it possible to conclude that the strength of the hatch cover at the given test base is ensured.

Strength of the hatch cover was also checked when impact load of $150 \mathrm{~kg}$ from a height of $3000 \mathrm{~mm}$ is dropping on it. The strength simulation of the hatch cover is shown in Fig. 7. Model was fixed by the earpiece of the cover and by the hinges joint. The model took in account that the hatch cover is loaded with its own weight. Results of the calculation are shown in Fig. 8. 


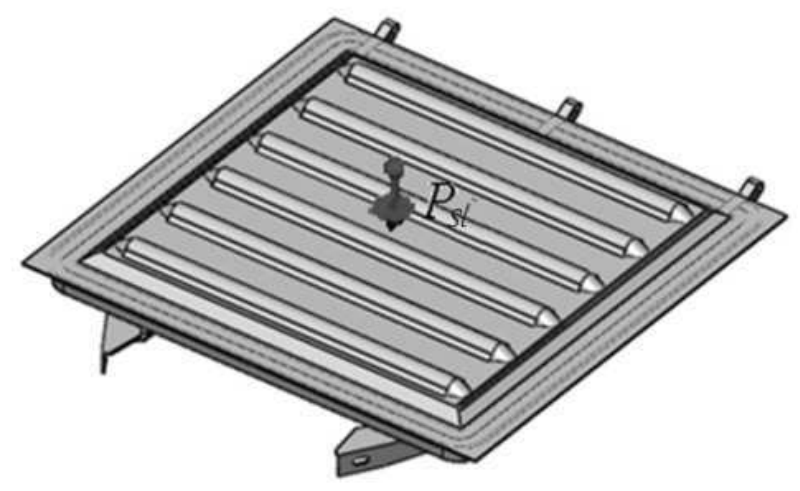

Fig. 7 Hatch cover simulation model (Psl-shock load which acts on the hatch cover while cargo impact)

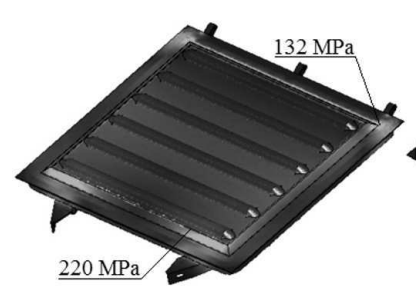

Fig. 8 Streses state of the hatch cov
bottom view

In case of non-rigid cover impact to the spine beam of the wagon frame, maximum equivalent stresses arise in the transition zone of rounding ribs to the horizontal plane on the side of locking latches, as well as in the W-shaped sheet from the hinges of the hatch cover mounting to the frame and is about $90 \mathrm{MPa}$. The maximum displacement in the mesh nodes is about $9 \mathrm{~mm}$, the maximum deformations were $2.68 \cdot 10^{-2}$. In this loading scheme, durability of the hatch cover is ensured.

Hatch cover strength model considering no-simultaneous locks opening (lying of the loaded wagon hatch cover on one lock and one hinge) is shown in Fig. 9.

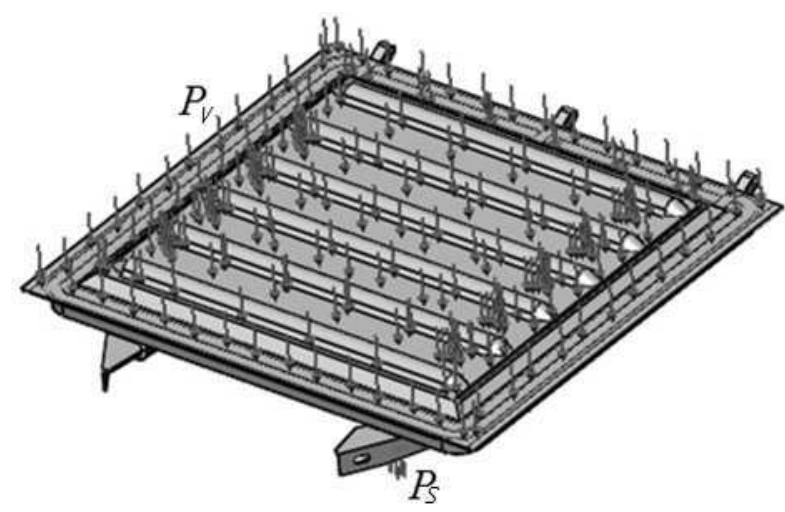

Fig. 9 Computer model for hatch cover strength analysis $\left(P_{v}-\right.$ vertical load; $P_{s}$ - reaction in the shut-off bracket to the load action $P_{s}$ )

Fixing of the model was provided by the hinghe. The vertical load was taken equal to $P_{v}=69.9 \mathrm{kN}$, the reaction
$P_{s}$ in the bracket to the action of the vertical load $P_{v}$ was applied to the locking device bracket in the zone of contact with the latch of the locking device.

In this case, maximum equivalent stresses are reached in the W-shaped sheet on the top corners of the hatch cover, near to the coupling hinge to the vagon frame. Values about $200 \mathrm{MPa}$ (Fig. 10) are reached. The maximum displacements in the design knots are about $9 \mathrm{~mm}$, the maximum deformations were $2.44 \cdot 10^{-2}$. That is, the hatch cover strength in this load cycle is ensured.
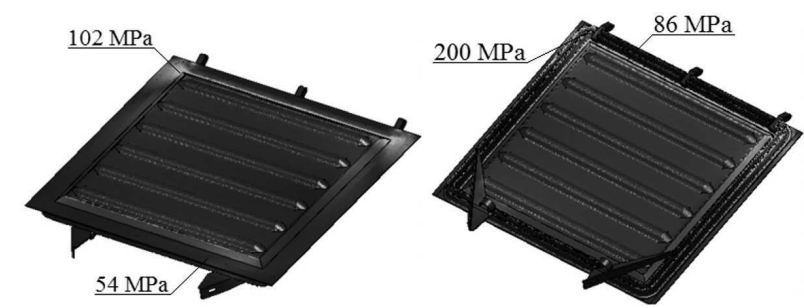

a)

b)

Fig. 10 The streses state of the hatch cover: a) top view; b) bottom view

In the case of hatch cover closing after wagon emptying by using of the crowbar, the maximum equivalent stresses arise in the $\mathrm{W}$-shaped sheet on the hinges site where joint to the wagon frame take place. In this corners, stresses about $100 \mathrm{MPa}$ occurs. The maximum displacement in the assembly nodes is $9 \mathrm{~mm}$, the maximum deformations were $2.44 \cdot 10^{-2}$. The strength of the hatch covers at a given load scheme is ensured.

The hatch cover construction consider also with durability in the most adverse load cases.

The lifetime of the hatch cover under cyclic load with a symmetric loading cycle can be determined by the fatigue reserve factor [19]:

$$
N=N_{o} \cdot n^{m},[\text { cycles }]
$$

where $N_{o}$ - test base [cycles];

$n$ - coefficient of fatigue resistance reserve [-]; $m$ - parameter of fatigue curve [-].

$$
n=\frac{\sigma_{-1}}{\sigma_{a}},[-]
$$

where $\sigma_{-1}-$ fatigue strength limit [MPa]; $\sigma_{-1}-$ tension amplitude [MPa].

$$
m=\frac{\ln N_{o}-\ln N}{\ln \sigma_{a}-\ln \sigma_{-1}}, \text { [-] }
$$

where $N$-number of cycles to destruction [cycles].

For steel, value of the fatigue strength limit can be determined:

$$
\sigma_{-1} \approx(0.1-0.5) \sigma_{v r},[M P a]
$$

where $\sigma_{v r}-$ strength limit $[\mathrm{MPa}$ ].

For the improved hatch cover construction, when $\sigma$. ${ }_{l}=245 \mathrm{MPa}$, for $N_{o}=10^{7}$ cycles can be established that its durability taking into account the symmetric loading cycle is ensured.

Assuming this same situation in the case of shock and a non-symmetric load, can be written: 


$$
N=\left\{\begin{array}{l}
N_{o} \cdot\left(\frac{\sigma_{-1}}{\sigma_{a}+\psi_{1} \cdot \sigma_{m}}\right)^{m}, \text { at } 0 \leq \sigma_{m} \leq \sigma^{*}, \sigma_{-1}-\psi_{1} \cdot \sigma_{m}<\sigma_{a} \leq \sigma_{s t r}-\sigma_{m} ; \\
N_{o} \cdot\left(\frac{\sigma_{-1}}{\sigma_{a}+\psi_{1} \cdot \sigma_{m}}\right)^{m}, \text { at } 0.5 \cdot \sigma_{-\infty} \leq \sigma_{m} \leq \sigma_{\Delta}, \sigma_{-1}-\psi_{2} \cdot \sigma_{m}<\sigma_{a} \leq \sigma_{s t r}-\sigma_{m}+, \text { [cycles] } \\
+\left|\sigma_{c o m}\right| \text { and also at }: \sigma_{\Delta}<\sigma_{m} \leq 0 ; \\
\sigma_{-1}-\psi_{1} \cdot \sigma_{m}<\sigma_{a} \leq \sigma_{s t r}-\sigma_{m},
\end{array}\right.
$$

where $\sigma_{m}$ - average stres value [MPa];

$\psi_{l}$ - parameter given by the following formula:

$$
\psi_{1}=\frac{2 \cdot \sigma_{-1}-\sigma_{o}}{\sigma_{o}},[-]
$$

$\psi_{2}$ - parameter given by the following formula:

$$
\psi_{2}=\frac{\sigma_{-\infty}-2 \cdot \sigma_{-1}}{\left|\sigma_{-\infty}\right|},[-]
$$

$\sigma_{s t r}-$ Yield strength when pulling [MPa];

$\sigma_{\text {com }}-$ Yield strength when pusshing, [MPa];

$\sigma_{-\infty}$ - fatigue strength limit for zero negative load mode, $[\mathrm{MPa}]$;

$\sigma_{\Delta}-$ maximum stress value, [MPa];

$\sigma^{*}-$ tension value according expression:

$$
\sigma^{*}=\frac{\sigma_{T . P .}-\sigma_{-1}}{\sigma_{o}},[M P a]
$$

$\sigma_{o}$ - fatigue strength limit for zero positive load mode [MPa].

If the fatigue strength limits $\sigma_{o}$ and $\sigma_{-\infty}$ are unknown, then a simplified boundary amplitude diagram is constructed. In this case:

$$
\psi_{1}=\frac{\sigma_{-1}}{\sigma_{v r}},[-]
$$

On the basis of theoretical strength calculations, the proposed hatch cover construction durability study is carried out according to the formula:

$$
N=N_{o} \cdot\left(\frac{\sigma_{-1}}{\sigma_{a}+\psi_{1} \cdot \sigma_{m}}\right)^{m}[\text { cycles }]
$$

The performed calculations showed that the durability of the hatch cover with a non-symmetric loading cycle is ensured.

\section{Conclusions}

1. The improved design of the hatch cover for the open cargo wagon is developed. The hatch cover feature is created by an elastic-viscous substance located between two horizontal sheets. This solution ensures $50 \%$ reduction of load under operation conditions.

2. The hatch cover strength calculation is carried out under the main and additional load modes. The results of the conducted studies allowed us to conclude that, taking into account measures to improve construction of the usual hatch cover, its strength under operating load conditions is ensured. In this case, the maximum equivalent stress occurs while test with scenario when $150 \mathrm{~kg}$ of cargo impacts from $3000 \mathrm{~mm}$ height. Cover stress takes in this case about $220 \mathrm{MPa}$. That is, do not exceed the permissible.

3. The durability calculation of the improved open wagon hatch cover construction for symmetric and asymmetric load cycle is carried out. The performed calculations showed that his durability for required test base is ensured.

\section{References}

[1] GORBUNOV, M., GERLICI, J., KARA, S., NOZHENKO, O., KRAVCHENKO, K., LACK, T. (2018). New principle schemes of freight cars bogies. In: Manufacturing Technology, Vol. 18, No. 2, pp. 233 - 238. Institute of Technology and Production Management University of J.E. Purkyne Publisher, Usti nad Labem.

[2] LACK, T., GERLICI, J. (2018). Y25 freight car bogie models properties analysis by means of computer simulations. In: MATEC Web of Conferences, Vol. 157, 03014. EDP Sciences.

[3] LACK, T., GERLICI, J., MANUROVA, M. (2016). Freight car bogie properties analysis by means of simulation computations. In: Manufacturing Technology, Vol. 16, No 4, pp. 733 - 739. Institute of Technology and Production Management University of J.E. Purkyne Publisher, Usti nad Labem.

[4] ŠTASTNIAK, P., MORAVČÍK, M., SMETANKA, L., BARAN, P. (2018). Strength investigation of Main Frame in New "Track friendly" Railway Bogie. In: Manufacturing Technology, Vol. 18, No. 2, pp. 315 - 320. Institute of Technology and Production Management University of J.E. Purkyne Publisher, Usti nad Labem.

[5] GERLICI, J., DOMIN, R., CHERNIAK, G., LACK, T. (2018). Calculated estimation of railway wheels equivalent conicity influence on critical speed of railway passenger car. In: MATEC Web of Conferences, Vol. 157, 03006. EDP Sciences.

[6] OKOROKOV, A.M., FOMIN, O.V., LOVSKA, A.O., VERNIGORA, R.V., ZHURAVEL, I.L., FOMIN V.V. (2018). Research into a possibility to prolong the time of operation of universal semiwagon bodies that have exhausted their standard resource. In: Eastern-European journal of enterprise technologies, Vol. 3, No 7-93, pp. $20-26$. PC Technology Center Publisher, Kharkov.

[7] STOTSKO, Z., KUZIN, M. (2018). Life cycle assessment of technical systems taking into conside- 
ration degradation processes in materials of constructions. Archives of Materials Science and Engineering. Vol. 89, No 1., pp. 5 - 8. International OCSCO World Press Publisher, Poland.

[8] GERASIMOV. K. V. (2017). Loading of the body of a gondola-type wagon when the lump of a cargo falls, Thesis, Bryansk State Technical University 20 p. Russia.

[9] FOMIN, O., LOVSKAYA, A., PLAKHTIY, A., NERUBATSKY V. (2017). The influence of implementation of circular pipes in load-bearing structures of bodies of freight cars on their physico-mechanical properties. Scientific Bulletin of National Mining University, No 6 (162), p.8996. National Mining University of Ukraine, $\mathrm{Pu}-$ blisher.

[10] PUTYATO, A.V. (2011). Modeling of the stressed-deformed state of the hatch cover of a wagon with falling pieces of cargo. In: Mechanics. Scientific research and teaching methods, №5, pp. 113 - 122. Belarusian State University of Transport Publisher, Belorussia.

[11] KEBAL, I. Yu., Myamlin, S.V. (2016). Perfection of the hatch cover of the wagon. In: Wagon fleet, No. 7-8, pp. 41-43. Ukraine.

[12] MYAMLIN, S. V., BARANOVSKIY, D. N., KEBAL, I. Yu. (2015). Hatch cover of universal open wagon. In: Bulletin of scientific works of Bryansk branch of MIIT: Collection of scientific works, Vol. 7, pp. 45 - 48. Design-Print Publisher, Russia.

[13] SKILLINGBERG, M., GREEN, J. (2007). Aluminum applications in the rail industry. In: Light metal age, October, pp. 1 - 5. Advontemedia $\mathrm{Pu}-$ blisher. USA.

[14] DIZO, J., HARUSINEC, J., BLATNICKY, M. (2017). Structural analysis of a modified freight wagon bogie frame. In: Matec Web of Conferences, Vol. 134, 00010, pp. 3 - 8. EDP Sciences.

[15] BLATNICKY, M., BARTA, D., DIZO, J., DROZDZIEL, P. (2017). Diagnosing of fatigue lifespan using the modern method of welding simulating, Diagnostyka Vol. 18, No. 4, pp. $19-26$. Poland.

[16] GERLICI, J., NOZHENKO, O., CHERNIAK, G., GORBUNOV, M., DOMIN, R., LACK, T. (2018). The development of diagnostics methodological principles of the railway rolling stock on the basis of the analysis of dynamic vibration processes of the rail. In: MATEC Web of Conferences, Vol. 157, 03007. EDP Sciences.

[17] FOMIN, O., KULBOVSKIY, I., SOROCHINSKA, E., SAPRONOVA, S., BAMBURA, O. (2017). Experimental confirmation of the theory of implementation of the coupled design of center girder of the hopper wagons for iron ore pellets. In: Eastern-European Journal of Enterprise Technologies, Vol. 5, No 1 (89), pp. 11 - 19. PC Technology Center Publisher, Kharkov.

[18] RAILWAY APPLICATIONS - STRUCTURAL REQUIREMENTS OF RAILWAY VEHICLE BODIES - Part 2: Freight wagons. EN 12663-2.

[19] USTICH, P.A., KARPYICH, V.A., OVECHNIKOV, M.N. (1999). Reliability of rail non-traction rolling stock. 415 p. IG "Variant", Moscow.

[20] KUZIN, N. O. (2015). A mathematical model describing the variation in material properties. In: International Applied Mechanics. Vol. 51, No. 4, pp. 125-132., pp. 474 - 479. Springer Nature Publisher. Switzerland. 